\title{
Lipid Replacement Therapy: a Functional Food Approach with New Formulations for Reducing Cellular Oxidative Damage, Cancer-Associated Fatigue and the Adverse Effects of Cancer Therapy
}

\author{
Garth L. Nicolson ${ }^{1}$ and Robert Settineri ${ }^{2}$ \\ ${ }^{1}$ Department of Molecular Pathology, The Institute for Molecular Medicine, Huntington Beach, \\ CA 92647 USA \\ ${ }^{2}$ Sierra Research, Irvine, CA, 92606 USA
}

Corresponding Author: Prof. Garth L. Nicolson, Department of Molecular Pathology, Institute for Molecular Medicine, P. O. Box 9355, S. Laguna Beach, CA 92652

Submission date: February 26, 2011; Acceptance date: April 21, 2011; Publication date: April 21,2011

\begin{abstract}
$\underline{\text { Abstract }}$
Background:

Cancer-associated fatigue and the chronic adverse effects of cancer therapy can be reduced by Lipid Replacement Therapy (LRT) using membrane phospholipid mixtures given as food supplements.
\end{abstract}

\section{Methods:}

This is a review of the published literature on LRT and its uses.

Results: LRT significantly reduced fatigue in cancer patients as well as patients suffering from chronic fatiguing illnesses and other medical conditions. It also reduced the adverse effects of chemotherapy, resulting in improvements in incidence of fatigue, nausea, diarrhea, impaired taste, constipation, insomnia and other quality of life indicators. In other diseases, such as chronic fatigue syndrome, fibromyalgia syndrome and other chronic fatiguing illnesses, LRT reduced fatigue by $35.5-43.1 \%$ in different clinical trials and increased mitochondrial function.

Conclusions: LRT formulations appear to be useful as non-toxic dietary supplements for direct use or placed in functional foods to reduce fatigue and restore mitochondrial and other cellular membrane functions. Formulations of LRT phospholipids are suitable for addition to various food products for the treatment of a variety of chronic illnesses as well as their application in anti-aging and other health supplements and products. 
Keywords: nutritional supplements, NT factor ${ }^{\circledR}$, Coenzyme $\mathrm{Q}_{10}$, cancer fatigue, mitochondria,

\section{Background}

Nutritional supplements are often taken to maintain health and prevent disease, but cancer patients routinely take multiple dietary supplements to prevent recurrence of cancer, reduce the adverse effects of cancer therapy and to improve quality of life [1-4]. Indeed, one of the most common changes in behavior among cancer patients is initiation of the use of multiple dietary supplements [3].

Studies conducted on the routine use of dietary supplements by cancer patients as well as cancer survivors indicate that there is often little consideration as to their safety, efficacy and potential negative effects $[5,6]$. In fact, some data suggest that higher than recommended doses of some vitamins and minerals might result in enhancement of carcinogenesis, changes in survival in some cancers and interference with therapy or prescription medications [5, 6]. In cancer patients several potentially beneficial effects of dietary supplements have been documented, including reductions in the risk of cancer carcinogenesis and tumor progression, enhancement of immune responses against cancer or immune systems in general, improvements in nutrition and general health, and reductions in the adverse effects of cancer therapy [3-5, 714]. Here we will focus on one of the most troublesome aspects of cancer and its therapy: cancer-associated fatigue.

\section{Introduction}

One of the most common symptoms in cancer that can add considerably to cancer morbidity is cancer-associated fatigue [13-16]. It exists in all types of cancers from the least to the most progressed cancers $[15,16]$. Along with pain and nausea, it is one of the most common and troublesome symptoms of cancer $[16,17]$. Cancer-associated fatigue is especially apparent in advanced cancers where the systemic adverse effects of cancer therapy are almost always present [17-19].

In advanced cancer patients receiving adjuvant therapies the prevalence of cancerassociated fatigue is reported to be as high as 95\% [20]. Thus cancer-associated fatigue is a problem before, during and after therapy, and it can continue to be a problem years after cancer treatment has stopped $[16,19]$. Cancer-associated fatigue has a very strong negative effect on quality of life; therefore, addressing and reducing cancer-associated fatigue should be an important consideration in the treatment of cancer $[14,19]$.

Although not well understood, cancer-associated fatigue is thought to be a combination of the effects of having cancer plus the effects of cancer treatments [16, 19]. Unfortunately, cancer-associated fatigue is rarely treated, and is often thought to be an unavoidable symptom $[15,16]$. Cancer-associated fatigue can be considered to be the product of a variety of contributing factors [21]. In addition to a decrease in the availability of cellular energy, such as 
provided by mitochondria, there exist psychological and medical factors that determine states of fatigue. The psychological factors include depression, anxiety, sleep disturbances, among others, and the medical factors include anemia, endocrine changes, poor nutritional status and release of inflammatory cytokines [11-14, 19-23]. All of these factors can all contribute to cancerassociated fatigue [12-14].

Cancer-associated fatigue does not occur as an isolated symptom. Cancer patients usually have a variety of symptoms, including cancer-associated fatigue. Cancer-associated fatigue occurs as one of multiple symptoms that are present at all stages of cancer, with exception of the very earliest stages. Cancer-associated fatigue is similar to many other symptoms in cancer patients, in that the severity of cancer-associated fatigue usually correlates with decreased functional abilities [24].

Cancer therapy also contributes in an important way to cancer-associated fatigue [19-21]. In fact, the most commonly found and disabling effect of cancer therapy is fatigue [20, 24, 25]. During cancer therapy fatigue problems can vary, from mild to severe, and excess fatigue during cancer therapy is an important reason given by patients when they discontinue therapy [26]. When Manzullo and Escalante [23] reviewed the literature on the effects of cancer therapy on cancer-associated fatigue, they found that $80-96 \%$ of patients receiving chemotherapy and 6093\% receiving radiotherapy experienced moderate to severe fatigue. Fatigue not only was a significant problem during cancer therapy, but it continued for months to years after the therapy ended [23]. Thus in cancer patients suppressing cancer-associated fatigue as well as controlling therapy-induced fatigue are important in supportive cancer care [27].

Recent research on cancer-associated fatigue has been directed at understanding and treating cancer-associated fatigue as well as developing ways to distinguish between depression and cancer-associated fatigue [15]. Depression is a common complaint of cancer patients. Both cancer-associated fatigue and depression have multidimensional and heterogeneous qualities. For example, they both possess physical, cognitive and emotional dimensions, and there is a certain degree of overlap across these dimensions [15, 20].

Fatigue or loss of energy is a core symptom in diagnosing depression. Thus both fatigue and depression are often diagnosed together. This is usually accomplished by self-assessment, where fatigue and depression are considered to be part of a clinical symptom cluster, comorbidity or syndrome $[28,29]$. There are procedures, however, that can distinguish between cancer-associated fatigue and depression by removal of fatigue-associated assessments from an analysis of depression [30,31]. Criteria have been established when assessing fatigue or cancerassociated fatigue that take depression into consideration, and these two symptoms can thus be separated from one another by considering unshared properties [32].

Chronic fatigue lasting more than 6 months that is not reversed by normal sleep is the most common complaint of patients seeking general medical care [33, 34]. Fatigue occurs naturally during aging, and it is also an important secondary condition in many clinical diagnoses $[34,35]$. Most patients understand fatigue as a loss of energy and inability to perform even 
simple tasks without exertion. Many medical conditions are associated with fatigue, including respiratory, coronary, musculoskeletal, and bowel conditions as well as infections [33-35]. Fatigue is the most common complaint made by the overwhelming majority of cancer patients $[16,19-21]$.

\section{Fatigue and its Relationship to Oxidative Stress and Damage to Mitochondria}

An important phenomenon associated with cancer and its progression as well as aging and agerelated degenerative diseases is oxidative stress [36-39]. Oxidative stress is caused by an intracellular excess of reactive oxygen (ROS) and nitrogen (RNS) free radical species over intracellular antioxidants. When this imbalance occurs, it results in oxidation of cellular structures, such as membrane lipids and proteins; it also causes mutation of mitochondrial and nuclear DNA [39-42]. The free radicals ROS and RNS are naturally occurring cellular oxidants that are usually present in low concentrations; they are important cellular regulators and are involved in gene expression, intracellular signaling, cell proliferation, antimicrobial defense and other normal cellular processes [43-45]. However, when ROS/RNS are in excess over cellular antioxidants, oxidative damage can occur to cellular structures [39, 44-46]. Recently Maes [47] proposed a link between excess oxidative stress and activation of ROS/RNS pathways, which is in turn linked to fatigue and fatiguing illnesses.

Cellular antioxidant defenses usually maintain ROS/RNS at appropriate concentrations that prevent excess oxidation of cellular structures [48-50]. Some of the endogenous cellular antioxidant defenses are mediated by glutathione peroxidase, catalase and superoxide dismutase, among other enzymes [51,52]. There are also low molecular weight dietary antioxidants that can affect anti-oxidant status [53, 54]. Some of these dietary antioxidants have been used as natural chemopreventive agents to shift the excess concentrations of oxidative molecules down to more physiological levels $[55,56]$.

Excess oxidative stress and its mediators (ROS/RNS) within cancer cells have been linked to promotion and progression of cancer malignancy (metastasis) [57-61]. To demonstrate this oxidative stress and antioxidant status have been examined in various malignant cancers, such as breast [58-62], prostate [63, 64], colorectal [65, 66], renal [67, 68], and other cancers [69-71]. In all of these different cancers ROS/RNS were in excess of cellular antioxidant concentrations, resulting in excess oxidative stress. Therefore, these cancers could have been induced as a consequence of excess ROS/RNS and oxidative damage to the genetic apparatus $[37,39,72]$. Even more likely than carcinogenesis is the progression of tumors that might not evolve to malignancy in the absence of excess oxidative stress [11-14].

\section{Excess Oxidative Stress and Severe Fatigue Caused by Cancer Therapy}

Cancer therapy, such as chemotherapy, can result in the generation of excess ROS/RNS [reviewed in 8,9,11,12]. Thus cancer therapy and the resulting production of excess oxidative stress can damage biological systems other than tumors $[8,9,11,12]$. During chemotherapy the 
highest known levels of oxidative stress are generated by anthracycline antibiotics, followed in no particular order by alkylating agents, platinum-coordination complexes, epipodophyllotoxins, and camptothecins $[8,9]$. The primary site of ROS/RNS generation during cancer chemotherapy is the cytochrome P450 monooxygenase system within liver microsomes. Enzyme systems, such as the xanthine-xanthine oxidase system, and non-enzymatic mechanisms (Fenton and HaberWeiss reactions) also play a role in creating excess oxidative stress during chemotherapy $[8,9]$. The very high levels of oxidative stress caused by anthracyclines is also related to their ability to displace coenzyme $\mathrm{Q}_{10}\left(\mathrm{CoQ}_{10}\right)$ from the electron transport system of cardiac mitochondria, resulting in diversion of electrons directly to molecular oxygen with the formation of superoxide radicals [reviewed in 8,9$]$.

Anthracyclines and other chemotherapeutic agents cause generation of high levels of ROS/RNS, but not all chemotherapeutic agents generate excess oxidative stress. Some agents generate only modest amounts of ROS/RNS. Examples of this are: platinum-coordination complexes and camptothecins, taxanes, vinca alkaloids, anti-metabolites, such as the anti-folates, and nucleoside and nucleotide analogues $[8,9,11,12]$. However, most chemotherapeutic agents generate some oxidative stress, as do all anti-neoplastic agents when they induce apoptosis in cancer cells $[8,9]$. Drug-induced apoptosis is usually triggered by the release of cytochrome c from the mitochondrial electron transport chain. When this occurs, electrons are diverted from NADH dehydrogenase and reduced $\mathrm{CoQ}_{10}$ to oxygen, resulting in the formation of superoxide radicals $[8,9,73]$.

Chemotherapeutic agents used to treat cancer cause oxidative stress, which produces side effects, and among the most common side effects is chronic fatigue [8, 9, 11, 12]. Chronic fatigue caused by cancer therapy can reduce therapeutic efficacy $[12,13]$. Although many antineoplastic agents have clearly established mechanisms of action that are not dependent upon the generation of ROS/RNS, these drugs can only mediate their anticancer effects on cancer cells that are exhibiting unrestricted progression through the cell cycle. They must also have intact apoptotic pathways. Thus oxidative stress interferes with cell cycle progression by inhibiting the transition of cells from the $\mathrm{G}_{0}$ to $\mathrm{G}_{1}$ phase, slowing progression through $\mathrm{S}$ phase by inhibition of DNA synthesis. This results in inhibition of cell cycle progression of the $G_{1}$ to $S$ phase, and it also results in inhibition by checkpoint arrest [74-78].

Chemotherapeutic agents can also activate DNA repair systems. DNA repair of damage caused by alkylating agents and platinum complexes results in resistance to these drugs, and checkpoint arrest during oxidative stress can enhance the repair processes and diminish the efficacy of treatment [79-81]. Abolishing checkpoint arrest produces the opposite effect and enhances the cytotoxicity of anti-neoplastic agents. By reducing oxidative stress, antioxidants counteract the effects of chemotherapy-induced oxidative stress on the cell cycle and enhance the cytotoxicity of antineoplastic agents $[8,9]$.

Important intracellular signal transduction pathways that are necessary for the action of some antineoplastic agents can also be affected by oxidative stress $[8,9,82,83]$. There are two 
major pathways of drug-induced apoptosis following cellular damage by anti-neoplastic agents: (1) The mitochondrial pathway, initiated by release of cytochrome c; and (2) the CD95 death receptor pathway, initiated by $\mathrm{CD} 95 \mathrm{~L}$ binding to its death receptor $[8,9,81]$. Oxidative stress during chemotherapy results in the generation of highly electrophilic aldehydes that have the ability to bind to the nucleophilic active sites of caspases as well as the extracellular domain of the CD95 death receptor. This inhibits caspase activity and the binding of CD96L ligand, resulting in impairment of the ability of anti-neoplastic agents to initiate apoptosis [82-84].

Similar to chemotherapy, radiotherapy also results in generation of oxidative stress and excess ROS/RNS $[85,86]$. The principal target of radiation in cancer cells is DNA, and DNA can be directly damaged by radiation. However, genetic damage is also mediated by excess ROS/RNS [86, 87]. Recently the principal source of excess ROS/RNS during radiotherapy has been shown to be mitochondrial $[87,88]$. Thus the initial cytotoxicity of radiation is now thought to be due to excess ROS/RNS, which triggers apoptosis via alteration of mitochondrial metabolism. This causes transiently opening of mitochondrial permeability transition pores, which increases the influx of calcium ions into the mitochondrial matrix. The influx of calcium ions stimulates mitochondrial nitric oxide synthase and generation of nitric oxide, which then inhibits the respiratory chain and eventually stimulates excess ROS/RNS free radicals that initiate apoptosis [88, 89].

\section{Cancer Therapy, its Adverse Side Effects and Damage to Cellular Mitochondria}

Cancer therapy is associated with several adverse side effects. One of the most difficult side effects is caused by chemotherapeutic drug (or radiotherapeutic) damage to mitochondria [8, 9, 11, 12]. Cardiac mitochondria are especially sensitive to certain chemotherapy agents, such as anthracycline antibiotics [8,9]. Anthracycline-induced cardiac toxicity is characterized by acute, reversible toxicity that causes electrocardiographic changes and depressed myocardial contractility and by chronic, irreversible, dose-related cardiomyopathy [9, 90]. The selective anthracycline-induced toxicity to cardiac cells is due to damage to cardiac mitochondria. The sensitivity of cardiac cells to anthracyclines, such as doxorubicin, has been found to be due to the unique properties of cardiac mitochondria, which possess a Complex I-associated NADH dehydrogenase in the inner mitochondrial membrane facing the mitochondrial cytosol [91, 92].

Small molecules can penetrate the outer mitochondrial membrane; thus doxorubicin as a relatively small molecule can readily penetrate the outer mitochondrial membrane [90, 93]. However, because it is hydrophilic and cannot partition into the lipid membrane matrix, it cannot penetrate the inner mitochondrial membrane [93]. Thus, it cannot participate in oxidationreduction reactions with the type of inner matrix-facing, electron transport chain dehydrogenases found in most types of cells, including most tumor cells [90, 93]. But in heart cells doxorubicin can interact with the mitochondrial cytosolic-facing NADH dehydrogenase that is unique to this tissue $[94,95]$. This interaction produces doxorubicin aglycones, which are highly lipid soluble 
and readily penetrate the inner mitochondrial membrane [90, 93]. At this location they can displace $\mathrm{CoQ}_{10}$ from the electron transport chain $[90,94]$.

The displacement of $\mathrm{CoQ}_{10}$ from the electron transport chain during doxorubicin treatment results in decreased $\mathrm{CoQ}_{10}$ in cardiac muscle [96]. This occurs as the plasma concentration of $\mathrm{CoQ}_{10}$ increases [97]. $\mathrm{CoQ}_{10}$ normally accepts electrons from Complexes I and II and transfers them down the electron transport chain, resulting in the formation of water. However, the presence of aglycones in the inner mitochondrial membrane and inner matrix results in the transfer the electrons directly to molecular oxygen, resulting in the formation of superoxide radicals [98]. Thus, doxorubicin generates a high level of oxidative stress in cardiac mitochondria, causing acute cardiac toxicity and damage to mitochondrial DNA [90, 95, 99].

Cardiac cells that are damaged by anthracyclines cannot sustain their function, and changes in their structure, mostly disruption of mitochondria, eventually results in apoptosis [90, 100]. This produces cardiac insufficiency and an inability to respond to pharmacological interventions, resulting ultimately in cardiac failure. However, if $\mathrm{CoQ}_{10}$ is administered during anthracycline chemotherapy, damage to the heart is prevented by decreases in anthracycline metabolism within cardiac mitochondria and by competing with aglycones for the $\mathrm{CoQ}_{10}$ sites within the electron transport chain $[8,9,90]$. Thus, $\operatorname{CoQ}_{10}$ administered concurrently with anthracyclines can maintain the integrity of cardiac mitochondria and prevent damage to the heart, and at the same time enhancing the anti-cancer activity of anthracyclines [8, 9, 90].

In addition to chemotherapy, radiotherapy also produces damage to tissues other than cancer tissues. Agents that protect tissues against radiation effects have been used to reduce unwanted damage [88, 101]. Such radioprotective agents that have been used to decrease the adverse effects of radiotherapy are: antioxidants, free radical scavengers, inhibitors of nitric oxide synthase and anti-inflammatory and immunomodulatory agents $[88,101]$. The most effective of these target mitochondria, such as proteins and peptides that can be transported into mitochondria and plasmids or nucleotide sequences. For example, agents that target and stimulate mitochondrial manganese superoxide dismutase genes can be used as radioprotective agents [88].

\section{Molecular Replacement of Mitochondrial Components During Cancer Therapy}

Replacement of $\mathrm{CoQ}_{10}$ during chemotherapy dramatically prevents development of anthracycline-induced cardiomyopathy and histopathological changes in heart tissue [9, 90]. Administering $\mathrm{CoQ}_{10}$ can also prevent changes in electrocardiograms (EKG) characteristic of anthracycline-induced heart damage [102]. In animals the administration of $\mathrm{CoQ}_{10}$ resulted in increased survival, improvement in their EKG patterns, and reduced heart histopathological changes [103]. These preclinical data, along with clinical data [discussed in 11, 12, 90] support the contention that $\mathrm{CoQ}_{10}$ protects the heart tissue from anthracycline-induced damage.

During chemotherapy with anthracyclines in some institutions cancer patients have received concurrent administration of $\mathrm{CoQ}_{10}$ to prevent both chronic and acute cardiotoxicity [9, 
$11,12,90]$. For example, the importance of administering $\mathrm{CoQ}_{10}$ on the development of doxorubicin-induced cardiotoxicity in patients with lung cancer has been studied by Judy et al. [104]. Doxorubicin given alone without $\mathrm{CoQ}_{10}$ caused marked impairment of cardiac function with a significant increase in heart rate and a substantial decrease in ejection fraction, stroke index and cardiac index. In contrast, doxorubicin administered along with $\mathrm{CoQ}_{10}$, did not cause cardiotoxicity, and cardiac function remained unchanged [104]. Other studies have confirmed these results and have shown that $\mathrm{CoQ}_{10}$ can reduce the cardiac toxicity of doxorubicin in adults $[105,106]$ and also in children $[107,108]$. Thus in preclinical and clinical studies the data indicate that $\mathrm{CoQ}_{10}$ protects the heart from the cardiotoxicity of anthracyclines.

\section{Cancer-Associated Fatigue and Other Adverse Effects of Therapy}

The most common complaint of patients undergoing anti-neoplastic therapy is fatigue, but there are also other complaints of patients that are undergoing cancer therapy [13,14]. These include: pain, nausea, vomiting, malaise, diarrhea, headaches, rashes and infections [23, 106, 108]. Other more serious problems can also occur, such as cardiomyopathy, peripheral neuropathy, hepatotoxicity, pulmonary fibrosis, mucositis and other effects caused by therapy [23, 26, 106, 108]. In terms of their cancer-associated fatigue, most patients feel that cancer therapy-caused fatigue is an untreatable symptom [25]. Although fatigue is usually the most commonly reported adverse symptom during cancer therapy, up until recently there was little effort directed at reducing fatigue before, during or after cancer therapy [109]. The perception that cancerassociated fatigue is an untreatable symptom has changed recently $[12,14]$.

Reducing cancer-associated fatigue and fatigue associated with cancer therapy are now considered important therapeutic goals. Psychological, physical, pharmaceutical and nutraceutical methods have been undertaken to reduce fatigue and improve the quality of life of cancer patients [14, 23, 111]. Such treatments are based mainly on suppressing fatigue but also on controlling co-morbid or related symptoms, such as pain, anemia, cachexia, sleep disorders, depression and other symptoms [14, 23, 111-115].

Unfortunately, there is no standard protocol related to treating cancer-associated fatigue and related symptoms. In reviewing the types of supportive measures used to control fatigue and related symptoms, the data suggest that graded exercise, nutritional support, treatment of psychological problems (such as depression with certain anti-depressants or psycostimulants), treatment of anemia with hematopoetic growth factors and control of insomnia with cognitive behavioral therapy or pharmacological and nonpharmacological therapies all have a role to various degrees in controlling cancer-associated fatigue [110-115]. Some of these approaches, such as the use of pharmacological drugs and growth factors, have been systematically metaanalyzed in 27 studies [116]. In this limited analysis, only a psycostimulant (methylphenidate) and hematopoetic growth factors (erythropoietin and darbopeitin) were more effective than placebo treatments. Other treatments were no better than placebo in the treatment of cancerrelated fatigue 116]. 


\section{Cancer-Associated Fatigue, Aging and Mitochondrial Membrane Damage}

As discussed above, cancer-associated fatigue has been defined as a multidimensional sensation $[14,35,112,113,116]$. Most patients understand fatigue as a loss of energy and inability to perform even simple tasks without exertion [116, 117]. Cancer-associated fatigue has been described as the dysregulation of several interrelated physiological, biochemical and psychological systems [112, 113], but at the tissue and cellular levels fatigue is related to reductions in the efficiency of cellular energy systems, mainly found in mitochondria [13, 14, 118]. Damage to mitochondrial components, mainly by ROS/RNS oxidation of membrane phospholipids, can impair mitochondrial function, and this can also result in oxidative damage to other cellular structures [reviewed 36, 42, 44]. Mitochondrial membranes and DNA are major targets of oxidative stress, and with aging ROS/RNS mitochondrial damage can accumulate [80, 119].

During aging and in certain medical conditions oxidative damage to mitochondrial membranes impairs mitochondrial function [80, 119, 120]. For example, in chronic fatigue syndrome patients evidence of oxidative damage to DNA and lipids exists $[120,121]$ as well as oxidized blood markers [122] and muscle membrane lipids [123] that are indicative of excess oxidative stress [124]. In chronic fatigue syndrome patients also have sustained elevated levels of peroxynitrite due to excess nitric oxide, which can result in lipid peroxidation and loss of mitochondrial function as well as changes in cytokine levels that exert a positive feedback on nitric oxide production, increasing the rate of membrane damage [126].

\section{Lipid Replacement Therapy of Oxidized Membrane Components and its Effect on Fatigue}

In cancer patients mitochondrial membranes as well as other cellular membranes are especially sensitive to oxidative damage by ROS/RNS, which occurs at high rates in cancer $[65,66,68-71$, 124]. Oxidation of membrane phospholipids alters their structure, affecting lipid fluidity, permeability and membrane function [124, 126, 127]. One of the most important events caused by ROS/RNS damage is loss of electron transport function, and this appears to be related to mitochondrial membrane lipid peroxidation. Membrane oxidation induces permeability changes in mitochondria, and this can cause loss of mitochondrial transmembrane potential, an essential requirement of oxidative phosphorylation [128, 129].

Lipid Replacement Therapy (LRT) has been used to reverse the accumulation of damaged phospholipids in mitochondria and other cellular membranes by replacing them with unoxidized phospholipids $[13,14,130]$. LRT plus antioxidants has been show to reverse ROS/RNS damage and increase mitochondrial function in certain fatiguing disorders, such as chronic fatigue, chronic fatigue syndrome and fibromyalgia syndrome $[118,131]$. LRT has been found to be effective in preventing ROS/RNS-associated changes and reversing mitochondrial damage and loss of function [reviewed in 14, 131]. 
LRT with unoxidized phospholipids and antioxidant supplements has been effective in replacement of damaged cellular and mitochondrial membrane phospholipids and other lipids that are essential structural and functional components of biological membranes [reviewed in 14, 131]. NTFactor ${ }^{\circledR}$, a LRT oral supplement containing phospholipids, phosphoglycolipids and other membrane lipids, has been used successfully in animal and clinical LRT studies [13, 14, $118,131,132]$. NTFactor's encapsulated lipids are protected from oxidation in the gut and can be absorbed and transported into tissues via lipid carriers without oxidation. Once inside cells the membrane lipids naturally replace oxidized, damaged membrane lipids by natural diffusion, and carrier proteins pick up the damaged lipids for degradation, transport and excretion [134].

In preclinical studies NTFactor ${ }^{\circledR}$ lipids have been used to reduce age-related functional damage, such as hearing loss associated with aging in rodents. NT Factor ${ }^{\circledR}$ lipids prevented hearing loss associated with aging and shifted the threshold hearing from 35-40 dB in control, aged rodents to 13-17 dB [134]. They also found that NT Factor ${ }^{\circledR}$ lipids preserved cochlear mitochondrial function and prevented aging-related mitochondrial DNA deletions found in the cochlear [134]. Thus NT Factor ${ }^{\circledR}$ lipids were successful in preventing age-associated hearing loss and reducing mitochondrial damage and DNA deletions in rodents [134].

In clinical studies LRT has been used to reduce fatigue and protect cellular and mitochondrial membranes from oxidative damage by ROS/RNS [reviewed in 13, 14, 131]. A LRT-vitamin mixture containing NT Factor ${ }^{\circledR}\left(\operatorname{Propax}^{\text {TM }}\right.$ with NT Factor®) was by used by Ellithorpe et al. [132] in a study of patients with severe chronic fatigue and was found to reduce their fatigue by approximately $40.5 \%$ in 8 weeks. In these studies fatigue was monitored by use of the Piper Fatigue Scale to measure clinical fatigue and quality of life [135]. In a subsequent study we examined the effects of NT Factor ${ }^{\circledR}$ on fatigue and mitochondrial function in patients with moderate to severe chronic fatigue [118]. Oral administration of NT Factor ${ }^{\circledR}$ for 12 weeks resulted in a $35.5 \%$ reduction in fatigue and $26.8 \%$ increase in mitochondrial function; whereas after a 12-week wash-out period fatigue increased and mitochondrial function decreased back towards control levels [118]. Thus in fatigued subjects dietary LRT can significantly improve and even restore mitochondrial function and significantly decrease fatigue. Similar findings were observed in chronic fatigue syndrome and fibromyalgia syndrome patients [131]. Recently a new formulation of NT Factor ${ }^{\circledR}$ plus vitamins, minerals and other supplements (Revacel ${ }^{\mathrm{TM}}$ with NT Factor®) resulted in a 36.8\% reduction in fatigue within one week [136] (Table 1).

\section{Lipid Replacement Therapy in Conjunction with Cancer Therapy}

LRT has been used to reduce the adverse effects of chemotherapy in cancer patients [reviewed in 14]. For example, a vitamin-mineral mixture with NTFactor (Propax ${ }^{\text {TM }}$ with NTFactor ${ }^{\circledR}$ ) has been used in cancer patients to reduce some of most common adverse effects of cancer therapy, such as chemotherapy-induced fatigue, nausea, vomiting, malaise, diarrhea, headaches and other side effects [137]. In two studies on patients with advanced metastatic colon, pancreatic or rectal 
cancers receiving a 12-week chemotherapy treatment schedule of 5-florouracil/ methotrexate/leukovorin LRT was used to reduce adverse effects of chemotherapy [137].

Table 1. Effects of dietary LRT supplement NTFactor on Piper Fatigue Scale scores. ${ }^{1}$

\begin{tabular}{lllll}
\hline & & Av & Time & Piper Fatigue Scale \\
Subjects/patients & $n$ & age & on LRT & fatigue reduction $(\%)$ Reference
\end{tabular}

$\begin{array}{lccccc}\text { Chronic fatigue }^{2} & 34 & 50.3 & 8 \mathrm{wks} & 40.5^{* *} & \text { Ellithorpe et al. [132] } \\ \text { Aging, chronic fatigue }^{3} & 20 & 68.9 & 12 \mathrm{wks} & 35.5^{*} & \text { Agadjanyan et al. [118] }\end{array}$

Chronic fatigue syndrome (and/or fibromyalgia

$\begin{array}{lccccc}\left.\text { syndrome }^{\#}\right)^{2} & 15 & 44.8 & 8 \mathrm{wks} & 43.1^{*} & \text { Nicolson \& Ellithorpe [131] } \\ \text { Obesity, fatigue }^{4} & 35 & 42 & 8 \mathrm{wks} & 24 * & \text { Nicolson et al. [138] } \\ \text { Aging, chronic fatigue }^{5} & 67 & 57.3 & 1 \mathrm{wk} & 36.8^{*} & \text { Nicolson et al. [136] }\end{array}$

${ }^{1}$ Modified from Nicolson [14]

${ }^{2} \operatorname{Propax}^{\mathrm{TM}}$ with NT Factor ${ }^{\circledR}$

${ }^{3}$ NT Factor ${ }^{\circledR}$

${ }^{4}$ Healthy Curb ${ }^{\mathrm{TM}}$ with NT Factor ${ }^{\circledR}$

${ }^{5}$ Advanced Physician's Formula ${ }^{\mathrm{TM}}$ or Revacel ${ }^{\mathrm{TM}}$ with NT Factor ${ }^{\circledR}$

$* * \mathrm{P}<0.0001, * \mathrm{P}<0.001$ compared to without NT Factor ${ }^{\circledR}$

\#5/15 fibromyalgia syndrome; $3 / 15$ chronic fatigue syndrome plus fibromyalgia syndrome

In the first unblinded part of the clinical study the effectiveness of NTFactor in a vitamin-mineral mixture $\left(\operatorname{Propax}^{\mathrm{TM}}\right.$ with NTFactor®) administered before and during chemotherapy was determined by examining signs and symptoms, and in particular, the side effects of therapy. A quality of life evaluation was conducted by a research nurse, and it was determined that patients on NTFactor supplementation experienced significantly fewer episodes of fatigue, nausea, diarrhea, constipation, skin changes, insomnia and other side effects [137]. In this open label trial $81 \%$ of patients demonstrated an overall improvement in quality of life parameters while on chemotherapy with LRT [137]. In the double-blinded, cross-over, placebo-controlled, randomized part of the study on advanced cancers the patients on chemotherapy plus LRT showed improvements in signs/symptoms associated with the adverse effects of chemotherapy [137]. Adding LRT resulted in improvements in the incidence of fatigue, nausea, diarrhea, impaired taste, constipation, insomnia and other quality of life indicators. Following cross-over from the placebo arm to the LRT arm, 57-70\% of patients on chemotherapy reported improvements in nausea, impaired taste, tiredness, appetite, sick feeling and other quality of life 
indicators [137] (Table 2). This clinical trial and other data clearly demonstrated the usefulness of LRT given during chemotherapy to reduce the adverse effects of cancer therapy [reviewed in $14]$.

Table 2. Effects of LRT (Propax ${ }^{\text {TM }}$ with NTFactor ${ }^{\circledR)}$ ) on the adverse effects of cancer chemotherapy in a cross-over clinical trial. ${ }^{1,2}$

\begin{tabular}{|c|c|c|c|c|}
\hline \multirow[b]{2}{*}{ First arm } & \multirow[b]{2}{*}{ Second arm } & \multicolumn{3}{|c|}{ Average $\%$ patients on test $\mathrm{arm}^{3}$} \\
\hline & & improvement & no change & worsening \\
\hline placebo & Propax $^{\mathrm{TM}}+\mathrm{NT}$ Factor ${ }^{\circledR}$ & 57 & 22 & 21 \\
\hline $\operatorname{Propax}^{\mathrm{TM}}+\mathrm{NT}$ Factor $\AA$ & placebo & 70 & 6 & 24 \\
\hline
\end{tabular}

${ }^{1}$ Table modified from Nicolson [14].

${ }^{2}$ The same regimen of 5-flurouracil/methotrexate/leukovoran was used for colon, pancreatic or rectal cancers.

${ }^{3}$ The percent of patients' self-reporting adverse effects was averaged with the percent of patients with adverse effects reported by a research nurse.

\section{Potential New Lipid Replacement Therapy Products and their Possible Uses}

In addition to use of LRT in cancer patients before, during and after their anti-cancer therapy, LRT has a number of other uses in many possible new products. Some of the possible new products containing LRT formulations are listed in Tables 3 and 4. For example, LRT formulations could have a variety of new uses as additives to functional foods (Table 3 ) or as condition-specific dietary supplements (Table 4). Some existing uses of LRT formulations in conditions other than cancer are as follows.

Table 3. Potential Functional Food products where LRT can be added.

\begin{tabular}{llll}
\hline Nutritional Products & Beverages & Dairy Products & Energy Foods \\
\hline Fruit powders & Energy drinks & Yogurts & Energy bars \\
Vegetable powders & Fruit drinks & Milk & Energy drinks \\
Protein powders & Vegetable drinks & Cheeses & Energy shots \\
Meal replacements & Soy milk & Sour cream & Antioxidant drinks \\
Cereals & Vitamin drinks & Cottage cheese & Cookies \\
Frozen foods & Probiotic drinks & Butter & Energy chews \\
Breads and bakery goods & Milk & Ice cream & Powders \\
Soups & & Soy ice cream &
\end{tabular}

Pet foods 
Table 4. Potential condition-specific dietary supplements with added LRT.

Amino acid supplements

Anti-aging supplements

Bone and joint supplements

Brain health supplements

Cellular support supplements

Digestive support supplements

Heart health supplements

Fiber supplements

Immune enhancement supplements

Inflammatory support supplements
Herbal supplements

Hormone supplements

Liver health supplements

Urinary health supplements

Mood relief supplements

Prostate health supplements

Sports performance supplements

Weight loss supplements

Multivitamin supplements

Essential fatty acid supplements

\section{LRT and Weight Loss}

Many individuals have weight issues or are obese, and weight reduction regimens that use drugs or stimulants can result in increased fatigue. We have studied the use of LRT in a weight loss clinical trial using a NT Factor® mixture with an FDA-approved amaylase inhibitor (Healthy Curb $^{\mathrm{TM}}$ ) [138]. The objective was to see if subjects could safely lose weight without increasing appetite or fatigue and without changing eating or exercise patterns or using drugs, herbs or caffeine. A 2-month open label clinical trial with Healthy $\operatorname{Curb}^{\mathrm{TM}}$ was initiated. Weight and measurements were taken weekly, appetite was assessed and fatigue was determined using the Piper Fatigue Scale [135]. We found that sixty-three percent of the participants lost an average of 6 pounds along with 2.5 and 1.5 inch reductions in waist and hip circumference, respectively, and the entire group of participants lost an average of 3 pounds with average reductions of 1.5 and 1 inch waist and hip circumference, respectively. Participants experienced gradual and consistent weight loss along with reductions in waist and hip measurements, body mass index (BMI) and basal metabolic rate (BMR) during the entire trial [138]. There was a $44 \%$ reduction in overall hunger with reduced cravings for sweets, and thus notable appetite suppression occurred during the trial. The entire test group showed an average of $24 \%$ decrease in overall fatigue. Blood lipid profiles generally improved, suggesting improved cardiovascular health, and no adverse effects were noted clinically or found in blood chemistries [138].

\section{LRT and Fatiguing Illnesses}

Fatiguing illnesses, such as chronic fatigue syndrome, fibromyalgia syndrome, Gulf War illness and other fatiguing illnesses can be successfully treated with LRT, such as NT Factor ${ }^{\circledR}$ and products containing NT Factor ${ }^{\circledR}$ (Table 1). In fatiguing illness patients use of products containing NT Factor ${ }^{\circledR}$ resulted in reductions in fatigue of approximately $35-43 \%$ (Table 1) $[118,131,132,136]$. In addition to fatigue, use of LRT in fatiguing illnesses patients also 
resulted in enhanced qualify of life and better mood, concentration, cognition and other symptoms [131, 132, 136], along with enhanced mitochondrial function [118].

\section{LRT and Anti-Aging Products}

LRT has the potential to reduce the effects of aging. In animal studies LRT reduced hearing loss and DNA mutations associated with aging [135]. In clinical trials using aged subjects (average age 68.9) LRT with NT Factor® significantly reduced fatigue by $35.5 \%$ in 12 weeks [118]. When mitochondrial function was assessed in these subjects, there was a $26.8 \%$ increase in mitochondrial function after LRT with NT Factor ${ }^{\circledR}$ to the levels found in much younger adults. After a 12-week wash-out period, fatigue increased and mitochondrial function decreased back towards control levels [118]. This indicated that LRT was effective in reversing some of the effects of aging, such as fatigue and loss of mitochondrial function. Anti-aging formulations, such as Healthy Aging $^{\mathrm{TM}}$ with NT Factor ${ }^{\circledR}$, have been used to repair damaged cellular membranes and reverse some of the other natural oxidative effects of aging.

\section{LRT and Degenerative Diseases}

Patients with neurodegenerative, neurobehavioral and metabolic illnesses all have problems with excess oxidation damage. For example, in the case of neurological diseases brain cells are particularly vulnerable to oxidative stress and damage caused by excess ROS/RNS. This is because of the brain's inability to withstand excess oxidative stress due to a high content of easily oxidized substrates (membrane phospholipids), relatively low levels of endogenous antioxidants, relatively high levels of endogenous generation of ROS and the endogenous generation of nitric oxide [139-141]. Antioxidant nutraceuticals (natural supplements, vitamins and minerals) have been proposed as a strategy to attenuate oxidative damage in neurological diseases [142]. In addition, LRT formulations, such as Healthy Aging ${ }^{\mathrm{TM}}$ with NT Factor®, contain a key brain phospholipid (phosphatidylserine) that improves brain "age-associated memory impairment," learning and cognitive performance that are impaired in dementing disorders like Alzheimer's disease [143]. LRT could also be used to repair oxidatively damaged brain structures, such as mitochondrial and cellular membranes, and reduce the damage caused by endogenous oxidation.

\section{LRT and Respiratory Diseases}

Asthma, chronic obstructive pulmonary disease and other respiratory conditions are characterized by inflammation and oxidative stress [144, 145]. Antioxidants have been proposed to attenuate the incidence and severity of respiratory attacks [145]. New products, such as Breathe Clear ${ }^{\mathrm{TM}}$ with NT Factor ${ }^{\circledR}$, have been used to reduce the symptoms of allergic and respiratory inflammation. In addition to NT Factor ${ }^{\circledR}$, Breathe Clear ${ }^{\mathrm{TM}}$ contains quercetin and other bioflavoids plus amino acids and L-taurine to reduce allergic inflammation and pulmonary 
reactions. Quercetin is a flavonol that helps modulate the release of histamine by mast cells [146].

\section{LRT and Cardiovascular Diseases}

Mitochondrial oxidative stress has been implicated, along with other factors, in cardiovascular disease and heart attack [147, 148]. Aging is accompanied by accumulation of cardiac mitochondrial membrane oxidation, increased mitochondrial DNA mutations as well as decreased production of critical cardiac proteins [147]. Vitamins, minerals, antioxidants and other supplements have been suggested as dietary approaches to reduce the risk of myocardial infarction and coronary disease $[149,150]$. LRT could play an important role in repairing cardiac mitochondrial and cellular membranes, an important role in cardiovascular health.

\section{LRT, Metabolic Syndrome (Pre-Diabetes) and Type 2 Diabetes}

One of the central defects in metabolic syndrome (a pre-diabetes, pre-cardiovascular disease syndrome) and its associated diseases (type-2 diabetes, vascular inflammation, atherosclerosis, among other diseases) is excess cellular oxidative stress [151, 152]. Nutritional supplements, vitamins, minerals, antioxidants and other supplements [151] as well as LRT with NT Factor are important new approaches, along with diet, weight management and lifestyle changes, for treating metabolic syndrome and preventing its associated diseases $[151,152]$.

\section{Conclusions}

Nutritional supplements have been used in a variety of diseases to provide patients with a natural, safe alternative to pharmacological drugs. In patients with cancer and other chronic illnesses nutritional supplements are often used for specific purposes or to improve quality of life. For example, cancer-associated fatigue is one of the most common symptoms in all forms and stages of cancer, but few patients receive assistance for their fatigue. Cancer-associated fatigue is associated with cellular oxidative stress, and during cancer therapy excess druginduced oxidative stress can cause a number of adverse effects, including: fatigue, nausea, vomiting and more serious effects. Cancer-associated fatigue and the adverse effects of cancer therapy can be reduced with LRT using natural phospholipid supplements that replace damaged membrane lipids along with providing antioxidants and enzymatic cofactors. Administering dietary LRT supplements can reduce oxidative membrane damage and restore mitochondrial and other cellular functions. Recent clinical trials using cancer and non-cancer patients with chronic fatigue have shown the benefits of specific LRT nutritional lipid supplements in reducing fatigue and restoring mitochondrial function. Newer formulations of LRT supplements will prove to be important additions in the treatment of a variety of chronic illnesses as well as useful additions to anti-aging and other health products.

\section{List of Abbreviations Used}


$\mathrm{CoQ}_{10}$, coenzyme $\mathrm{Q}_{10}$; EKG, electrocardiogram; FDA, Food and Drug Administration; LRT, Lipid Replacement Therapy; RNS, Nitrogen Reactive Species; ROS, Reactive Oxygen Species

\section{Competing Interests}

The authors have no financial interests or conflicts of interest.

\section{Authors' Contributions}

Both authors contributed to this review.

\section{Acknowledgements and Funding}

The authors would like to thank Rita Ellithorpe, M.D., for clinical advice and support, and Nutritional Therapeutics, Inc. and Researched Nutritionals, Inc. for research and clinical trial financial support.

\section{References}

1. Velicer CM, Ulrich CM. Vitamin and mineral supplement use among U.S. adults after cancer diagnosis: a systematic review. J Clin Oncol 2008; 26: 665-673.

2. Gansler T, Kaw C, Crammer C, Smith T. A population-based study of prevalence of complementary methods use by cancer survivors. Cancer 2008; 113: 1048-1057.

3. Miller PE, Vasey JJ, Short PF, Hartman TJ. Dietary supplement use in adult cancer survivors. Oncol Nurs Forum 2009; 36(1): 61-68.

4. Strahle A, Zanker K, Hahn, A. Nutrition in oncology: the case of micronutrients. Oncol Rep 2010; 24: 815-828.

5. Cassileth BR, Heitzer M, Wesa K. The public health impact of herbs and nutritional supplements. Pharmaceut Biol 2009; 47: 761-767.

6. Giovannucci E, Chan AT. Role of vitamin and mineral supplementation and aspirin use in cancer survivors. J Clin Oncol 2010; 28: 4081-4085.

7. Doyle C, Kushi LH, Byers T, Courneya KS, Denmark-Wahnefried W, Grant B, McTieran A, Rock CL, Thompson C, Gansler T, Andrews KS. Nutrition ad physical activity during and after cancer treatment: an American Cancer Society guide for informed choices. CA Cancer J 2006; 56: 323-353.

8. Conklin KA. Dietary antioxidants during cancer chemotherapy: impact on chemotherapeutic effectiveness and development of side effects. Nutr Cancer 2000; 37: $1-18$.

9. Conklin KA. Chemotherapy-associated oxidative stress: impact on chemotherapeutic effectiveness. Integr Cancer Ther 2004; 3: 294-300. 
10. Isenring E, Cross G, Kellett, E, Koczwara B. Nutritional status and information needs of medical oncology patients receiving treatment at an Australian public hospital. Nutr Cancer 2010; 62: 220-228.

11. Conklin KA, Nicolson GL. Molecular replacement in cancer therapy: reversing cancer metabolic and mitochondrial dysfunction, fatigue and the adverse effects of therapy. Curr Cancer Ther Rev 2008; 4: 66-76.

12. Nicolson GL, Conklin KA. Reversing mitochondrial dysfunction, fatigue and the adverse effects of chemotherapy of metastatic disease by Molecular Replacement Therapy. Clin Expl Metastasis 2008; 25: 161-169.

13. Nicolson GL. Lipid replacement/antioxidant therapy as an adjunct supplement to reduce the adverse effects of cancer therapy and restore mitochondrial function. Pathol Oncol Res 2005; 11: 139-144.

14. Nicolson GL. Lipid Replacement Therapy: a nutraceutical approach for reducing cancerassociated fatigue and the adverse effects of cancer therapy while restoring mitochondrial function. Cancer Metastasis Rev 2010; 29: 543-552.

15. Brown LF, Kroenke K. Cancer-related fatigue and its association with depression and anxiety: a systematic review. Psychosomat 2009; 50: 440-447.

16. Hofman M, Ryan JL, Figueroa-Moseley CD, Kohli S, Fiscella K, Palesh OG, Morrow GR. Cancer-related fatigue: the scale of the problem. Oncologist 2007; 12: 4-10.

17. Prue G, Rankin J, Allen J, Gracey J, Cramp F. Cancer-related fatigue: a critical appraisal. Eur J Cancer 2006; 42: 846-863.

18. Respini D, Jacobsen PB, Thors C, Tralongo P, Balducci L. The prevalence and correlates of fatigue in older cancer patients. Crit Rev Oncol Hematol 2003; 47: 273-279.

19. Curt GA, Breitbart W, Cella D, Groopman JE, Horning SJ, Itri LM, Johnson DH, Miaskowski C, Scherr SL, Portenoy RK, Vogelzang NJ. Impact of cancer-related fatigue on the lives of patients: new findings from The Fatigue Coalition. Oncologist 2000; 5: 353-360.

20. Sood A, Moynihan TJ. Cancer-related fatigue: an update. Curr Oncol Rep 2005; 7: $277-$ 282.

21. Ahlberg K, Ekman T, Gaston-Johansson F, Mock, V. Assessment and management of cancer-related fatigue in adults. Lancet 2003; 362(9384): 640-650.

22. Gutstein HB. The biological basis for fatigue. Cancer 2001; 92: 1678-1683.

23. Manzullo EF, Escalante CP. Research into fatigue. Hematol Oncol Clinics North Am 2002; 16: 619-628.

24. Given B, Given C, Azzouz F, Stommel M. Physical functioning of elderly cancer patients prior to diagnosis and following initial treatment. Nurs Res 2001; 50: 222-232.

25. Vogelzang N, Breitbart W, Cella D, Curt GA, Groopman JE, Horning SJ, Itri LM, Johnson DH, Scherr SL, Portenoy RK. Patient caregiver and oncologist perceptions of 
cancer-related fatigue: results of a tripart assessment survey. Semin Hematol 1997; 34(Suppl 2): 4-12.

26. Liu L, Marler MR, Parker BA, Jones V, Johnson S, Cohen-Zion M, Firoentino L, Sadler GR, Ancoli-Israel S. The relationship between fatigue and light exposure during chemotherapy. Supp Care Cancer 2005; 13: 1010-1017.

27. Marrow GR. Cancer-related fatigue: causes, consequences and management. Oncologist 2007; 12(suppl 1): 1-3.

28. Arnold LM. Understanding fatigue in major depressive disorder and other medical disorders. Psychosomat 2008; 49: 185-190.

29. Bender CM, Engberg SJ, Donovan HS, Cohen SM, Houze MP, Rosenzweig MQ, Mallory GA, Dunbar-Jacob J, Sereika SM. Symptom clusters in adults with chronic health problems and cancer as a co-morbidity. Oncol Nurs Forum 2008; 35(1): E1-E11.

30. Smets EMA, Garssen B, Cull A, de Haes JC. Applications of the Multidimensional Fatigue Inventory (MFI-20) in cancer patients receiving radiotherapy. Br J Cancer 1996; 73(2): 241-245.

31. Stone P, Hardy J, Huddart R, Ahern R, Richards M. Fatigue in patients with prostate cancer receiving hormone therapy. Eur J Cancer 2000; 36: 1134-1141.

32. Cella D, Davis K, Breitbart W, Curt G. Cancer-related fatigue: prevalence of proposed diagnostic criteria in a United States sample of cancer survivors. J Clin Oncol 2001; 19: 3385-3391.

33. Morrison JD. Fatigue as a presenting complaint in family practice. J Family Pract 1980; 10: 795-801.

34. Kroenke K, Wood DR, Mangelsdorff AD, Meier NJ, Powell JB. Chronic fatigue in primary care. Prevalence, patient characteristics, and outcome. JAMA 1988; 260: 929934.

35. McDonald E, David AS, Pelosi AJ, Mann AH. Chronic fatigue in primary care attendees. Psycholog Med 1993; 23: 987-998.

36. Kehrer JP. Free radicals and mediators of tissue injury and disease. Crit Rev Toxicol 1993; 23: 21-48.

37. Dreher D, Junod AF. Role of oxygen free radicals in cancer development. Eur J Cancer 1996; 32A: 30-38.

38. Halliwell B. Oxidative stress, nutrition and health. Free Radical Res 1996; 25: 57-74.

39. Abidi S, Ali A. Role of oxygen free radicals in the pathogenesis and etiology of cancer. Cancer Letters 1999; 142: 1-9.

40. Marnett LJ. Oxyradicals and DNA damage. Carcinogenesis 2000; 21: 361-370.

41. Stadtman E. Introduction to serial reviews on oxidatively modified proteins in aging and disease. Free Radical Biol Med 2002; 32: 789.

42. Bartsch H, Nair J. Oxidative stress and lipid peroxidation-driven DNA-lesions in inflammation driven carcinogenesis. Cancer Detect Prevent 2004; 28: 385-391. 
43. Johnson TM, Yu ZX, Ferrans VJ, Lowenstein RA, Finkel T. Reactive oxygen species are downstream mediators of p53-dependent apoptosis. Proc Nat Acad Sci USA 1996; 93: 11848-11852.

44. Castro L, Freeman BA. Reactive oxygen species in human health and disease. Nutr 2001; 17: 295-307.

45. Ghaffari S. Oxidative stress in the regulation of normal and neoplastic hematopoiesis. Antioxid Redox Signal 2008; 10: 1923-1940.

46. Maes M, Twisk FN. Why myalgic encephalomyelitis/chronic fatigue syndrome (ME/CFS) may kill you: disorders in the inflammatory and oxidative and nitrosative stress (IO\&NS) pathways may explain cardiovascular disorders in ME/CFS. NeuroEndocrinol Lett 2009; 30: 677-693.

47. Maes M. Inflammatory and oxidative and nitrosative stress pathways underpinning chronic fatigue, somatization and psychosomatic symptoms. Curr Opin Psychiat 2009; 22: 75-83.

48. Barber DA, Harris SR. Oxygen free radicals and antioxidants: a review. Am Pharmacol 1994; 34: 26-35.

49. Sun Y. Free radicals, antioxidant enzymes and carcinogenesis. Free Radical Biol Med 1990; 8: 583-599.

50. Fridovich I. Superoxide radical and superoxide dismutases. Annu Rev Biochem 1995; 64: 97-112.

51. Jagetia GC, Rajanikant GK, Rao SK, Shrinath Baliga M. Alteration in the glutathione, glutathione peroxidase, superoxide dismutase and lipid peroxidation by ascorbic acid in the skin of mice exposed to fractionated gamma radiation. Clin Chimica Acta 2003; 332: 111-121.

52. Seifried HE, McDonald SS, Anderson DE, Greenwald P, Milner JA. The antioxidant conundrum in cancer. Cancer Res 2003; 63: 4295-4298.

53. Aeschbach R, Loliger J, Scott BC, Murcia A, Butler J, Halliwell B, Anuoma OI. (1994). Antioxidant actions of thymol, carvacrol, 6-gingerol, zingerone and hydroxytyrosol. Food Chem Tox 1994; 32: 31-36.

54. Schwartz JL. The dual roles of nutrients as antioxidants and prooxidants: their effects on tumor cell growth. J Nutr 1996; 126: 1221S-1227S.

55. Tanaka T. Cancer chemoprevention by natural products. Oncol Rep 1994; 1: 1139-1155.

56. Prasad KN, Cole WC, Kumar B, Prasad KC. Scientific rationale for using high-dose multiple micronutrients as an adjunct to standard and experimental cancer therapies. J Am Coll Nutr 2001; 20: 450S-453S.

57. Toyokuni S, Okamoto K, Yodio J, Hiai H. Persistent oxidative stress in cancer. FEBS Lett 1995; 358: 1-3. 
58. Ray G, Batra S, Shukla NK, Deo S, Raina V, Ashok S, Husain SA. Lipid peroxidation, free radical production and antioxidant status in breast cancer. Breast Cancer Res Treat 2000; 59: 163-170.

59. Brown NS, Bicknell R. Hypoxia and oxidative stress in breast cancer. Oxidative stress: its effects on the growth, metastatic potential and response to therapy of breast cancer. Breast Cancer Res 2001; 3: 323-327.

60. Klaunig JE, Kamendulis LM. The role of oxidative stress in carcinogenesis. Annu Rev Pharm Toxicol 2004; 44: 239-267.

61. Tas F, Hansel H, Belce A, Llvan S, Argon A, Camlica H, Topuz E. Oxidative stress in breast cancer. Med Oncol 2005; 22: 11-105.

62. Kang DH. Oxidative stress, DNA damage and breast cancer. AACN Clin Issues 2002; 13: 540-549.

63. Sikka SC. Role of oxidative stress response elements and antioxidants in prostate cancer pathobiology and chemoprevention - a mechanistic approach. Curr Medicin Chem 2003; 10: 2679-2692.

64. Aydin A, Arsova-Sarafinovska Z, Sayal A, Eken A, Erdem O, Erten K, Ozgok Y, Dimovski A. Oxidative stress and antioxidant status in non-metastatic prostate cancer and benign prostate hyperplasia. Clin Biochem 2006; 39: 176-179.

65. Otamiri T, Sjodahl R. Increased lipid peroxidation in malignant tissues of patients with colorectal cancer. Cancer 1989; 64: 422-425.

66. Ozdemirler G, Pabuccuoglu H, Bulut T, Bugra D, Uysal M, Toker G. Increased lipoperoxide levels and antioxidant system in colorectal cancer. J Cancer Res Clin Oncol 1998; 124: 555-559.

67. Asal NR, Risser DR, Kadamani S, Geyer JR, Lee ET, Chemg N. Risk factors in renal cell carcinoma. I. Methodology, demographics, tobacco, beverage use, and obesity. Cancer Detect Prev 1990; 11: 359-377.

68. Gago-Dominguez M, Castelao JE, Yuan JM, Ross RK, Yu MC. Lipid peroxidation: a novel and unifying concept of the etiology of renal cell carcinoma. Cancer Causes Control 2002; 13: 287-293.

69. Seril DN, Liao J, Yang GY, Yang CS. Oxidative stress and ulcerative colitis-associated carcinogenesis: studies in humans and animal models. Carcinogenesis 2003; 24: 353-362.

70. Manoharan S, Kolanjiappan K, Suresh K, Panjamurthy K. Lipid peroxidation and antioxidants status in patients with oral squamous cell carcinoma. Indian J Med Res 2005; 122: 529-534.

71. Batcioglu K, Mehmet N, Ozturk IC, Yilmaz M, Aydogdu N, Erguvan R, Uyumlu B, Genc M, Karagozler AA. Lipid peroxidation and antioxidant status in stomach cancer. Cancer Invest 2006; 24: 18-21. 
72. Jaruga P, Zastawny TH, Skokowski J, Dizdaroglu M, Olinksi R. Oxidative DNA base damage and antioxidant enzyme activities in human lung cancer. FEBS Lett 1992; 341: 59-64.

73. Betteridge DJ. What is oxidative stress? Metabolism 2000; 49(suppl 1): 3-8.

74. Balin AK, Goodman DBP, Rasmussen H, Cristofalo VJ. Oxygen-sensitive stages of the cell cycle of human diploid cells. J Cell Biol 1978; 78: 390-400.

75. Hauptlorenz S, Esterbauer H, Moll W, Pumpel R, Schauenstein E, Puschendorf B. Effects of the lipid peroxidation product 4-hydroxynonenal and related aldehydes on proliferation and viability of cultured Ehrlich ascites tumor cells. Biochem Pharmacol 1985; 34: 38033809.

76. Gonzalez MJ. Lipid peroxidation and tumor growth: an inverse relationship. Med Hypoth 1992; 38: 106-110.

77. Kurata S. Selective activation of p38 MAPK cascade and mitotic arrest caused by low level oxidative stress. J Biol Chem 2000; 275: 23413-23416.

78. Schackelford RE, Kaufmann WK, Paules RS. Oxidative stress and cell cycle checkpoint function. Free Rad Biol Med 2000; 28: 1387-1404.

79. Zhen W, Link CJ, O'Connor PM, Reed E, Parker R, Howell SB, Bohr VA. Increased gene-specific repair of cisplatin interstrand cross-links in cisplatin-resistant human ovarian cancer cell lines. Mol Cell Biol 1992; 12: 3689-3698.

80. Wei YH, Lee HC. Oxidative stress, mitochondrial DNA mutation and impairment of antioxidant enzymes in aging. Exp Biol Med 2002; 227: 671-682.

81. Fojo T. Cancer, DNA repair mechanisms, and resistance to chemotherapy. J Nat Cancer Inst 2001; 93: 1434-1436.

82. Hampton MB, Fadeel B, Orrenius S. Redox regulation of the caspases during apoptosis. Ann N York Acad Sci 1998; 854: 328-335.

83. Shacter E, Williams JA, Hinson RM, Senturker S, Lee YJ. Oxidative stress interferes with cancer chemotherapy: inhibition of lymphoma cell apoptosis and phagocytosis. Blood 2000; 96: 307-313.

84. Chandra J, Samali A, Orrenius S. Triggering and modulation of apoptosis by oxidative stress. Free Rad Biol Med 2000; 29: 323-333.

85. Greenberger JS, Kagan VE, Pearce L, Boriseniao G, Tyurina Y, Epperly MW. Modulation of redox signal transduction pathways in the treatment of cancer. Antioxid Redox Signal 2001; 3: 347-359.

86. Feinendegen LE, Pollycove M, Neumann RD. Whole-body responses to low-level radiation exposure: New concepts in mammalian radiobiology. Exp Hematol 2007; 35: 37-46.

87. Epperly MW, Gretton JE, Sikora CA, Jefferson M, Bernarding M, Nie S, Greenberger JS. Mitochondrial localization of superoxide dismutase is required for decreasing radiationinduced cellular damage. Radiat Res 2003; 160: 568-578. 
88. Sabbarova I, Kanai A. Targeted delivery of radioprotective agents to mitochondria. Mol Intervent 2007; 8: 295-302.

89. Leach JK, Black SM, Schmidt-Ullrich RK, Mikkelsen RB. Activation of constitutive nitric-oxide synthase activity is an early signaling event induced by ionizing radiation. $\mathrm{J}$ Biol Chem 2002; 277: 15400-15406.

90. Conklin KA. Coenzyme $\mathrm{Q}_{10}$ for prevention of anthracycline-induced cardiotoxicity. Integr Cancer Ther 2005; 4: 110-130.

91. Lehninger AL. Phosphorylation coupled to oxidation of dihydrodiphosphopyridine nucleotide. J Biol Chem 1951; 190: 345-359.

92. Rasmussen UF, Rasmussen HN. The NADH oxidase system (external) of muscle mitochondria and its role in the oxidation of cytoplasmic NADH. Biochem J 1985; 229: 632-641.

93. Nohl H. Demonstration of the existence of an organo-specific NADH dehydrogenase in heart mitochondria. Eur J Biochem 1987; 169: 585-591.

94. Davies KJA, Doroshow JH. Redox cycling of anthracyclines by cardiac mitochondria. I. Anthracycline radical formation by NADH dehydrogenase. J Biol Chem 1986; 261: 3060-3067.

95. Doroshow JH, Davies KJA. (1986). Redox cycling of anthracyclines by cardiac mitochondria. II. Formation of superoxide anion, hydrogen peroxide, and hydroxyl radical. J Biol Chem 1986; 261: 3068-3074.

96. Karlsson J, Folkers K, Astrom H. Effect of Adriamycin on heart and skeletal muscle coenzyme $\mathrm{Q}_{10}\left(\mathrm{CoQ}_{10}\right)$ in man, in Folkers $\mathrm{K}$, Yamamura $\mathrm{Y}$, eds. Biomedical and Clinical Aspects of Coenzyme Q, Vol. 5, Amsterdam: Elsevier/North-Holland Biomedical Press, 1986, pp. 241-245.

97. Eaton S, Skinner R, Hale JP, Pourfarzam M, Roberts A, Price L, Bartlett K. Plasma coenzyme $\mathrm{Q}_{10}$ in children and adolescents undergoing doxorubicin therapy. Clin Chim Acta 2000; 302: 1-9.

98. Papadopoulou LC, Tsiftsoglou AS. Effects of hemin on apoptosis, suppression of cytochrome $\mathrm{C}$ oxidase gene expression, and bone-marrow toxicity induced by doxorubicin. Biochem Pharmacol 1996; 52: 713-722.

99. Palmeira CM, Serrano J, Kuehl DW, Wallace KB. Preferential oxidation of cardiac mitochondrial DNA following acute intoxication with doxorubicin. Biochim Biophys Acta 1997; 1321: 101-106.

100. Gille L, Nohl H. Analyses of the molecular mechanism of Adriamycin-induced cardiotoxicity. Free Rad Biol Med 1997; 23: 775-782.

101. Brizel DM. Pharmacologic approaches to radiation protection. J Clin Oncol 2007; 25: 4084-4089. 
102. Domae N, Sawada H, Matsuyama E, Konishi T, Uchino H. Cardiomyopathy and other chronic toxic effects induced in rabbits by doxorubicin and possible prevention by coenzyme $\mathrm{Q}_{10}$. Cancer Treat Rep 1981; 65: 79-91.

103. Usui T, Ishikura H, Izumi Y, Konishi H, Dohmae N, Sawada H, Uchino H, Matsuda H, Konishi T. Possible prevention from the progression of cardiotoxicity in Adriamycintreated rabbits by coenzyme $\mathrm{Q}_{10}$. Toxicol Lett 1982; 12: 75-82.

104. Judy WV, Hall JH, Dugan W, Toth PD, Folkers K. Coenzyme $\mathrm{Q}_{10}$ reduction of Adriamycin cardiotoxicity, in Folkers K, Yamamura Y, eds. Biomedical and Clinical Aspects of Coenzyme Q, vol 4, Amsterdam: Elsevier/North-Holland Biomedical Press, 1984, pp. 231-241.

105. Cortes EP, Gupta M, Chou C, Amin VC, Folkers K. Adriamycin cardiotoxicity: early detection by systolic time interval and possible prevention by coenzyme $\mathrm{Q}_{10}$. Cancer Treat Rep 1978; 62: 887-891.

106. Buckingham R, Fitt J, Sitzia J. Patients experience of chemotherapy: side-effects of carboplatin in the treatment of carcinoma of the ovary. Eur J Cancer Care 1997; 6: 59-71.

107. Iarussi D, Auricchio U, Agretto A, Murano A, Giuliano M, Casale F, Indolfi P, Iacono A. Protective effect of coenzyme $\mathrm{Q}_{10}$ on anthracyclines cardiotoxicity: control study in children with acute lymphoblastic leukemia and non-Hodgkin lymphoma. Mol Aspects Med 1994; 15(suppl): S207-S212.

108. Loke YK, Price D, Derry S, Aronson JK. Case reports of suspected adverse drug reactions--systematic literature survey of follow-up. Br Med J 2006; 232: 335-339.

109. Von Roenn JH, Paice JA. Control of common, non-pain cancer symptoms. Semin Oncol 2005; 32: 200-210.

110. Borneman T, Piper BF, Sun VC, Koczywas M, Uman G, Ferrell B. Implementing the fatigue guidelines at one NCCN member institution: process and outcomes. J Natl Compr Cancer Netw 2007; 5: 1092-1101.

111. Escalante CP, Kallen MA, Valdres RU, Morrow PK, Manzullo EF. Outcomes of a cancer-related fatigue clinic in a comprehensive cancer center. J Pain Symptom Manage 2011; 39: 691-701.

112. Ryan JL, Carroll JK, Ryan EP, Mustian KM, Fiscella K, Morrow GR. Mechanisms of cancer-related fatigue. Oncologist 2007; 12(Supp 1): 22-34.

113. Mustian KM, Morrow GR, Carroll JK, Figueroa-Moseley CD, Jean-Pierre P, Williams GC. Integrative nonpharmacological behavioral interventions for the management of cancer-related fatigue. Oncologist 2007; 12(Suppl 1): 52-67.

114. Watson T, Mock V. Exercise as an intervention for cancer-related fatigue. Phys Ther 2004; 84: 736-743.

115. Zee PC, Acoli-Isreal S. Does effective management of sleep disorders reduce cancerrelated fatigue? Drugs 2009; 69(Suppl 2): 29-41. 
116. Minton O, Richardson A, Sharpe M, Hotopf M, Stone P. A systematic review and metaanalysis of the pharmacological treatment of cancer-related fatigue. J Nat Cancer Inst 2008; 100: 1155-1166.

117. Levy M. Cancer fatigue: a review for psychiatrists. Gen Hosp Psychiat 2008; 30: 233244.

118. Agadjanyan M, Vasilevko V, Ghochikyan A, Berns P, Kesslak, P, Settineri, Nicolson GL. Nutritional supplement (NTFactor) restores mitochondrial function and reduces moderately severe fatigue in aged subjects. J Chronic Fatigue Syndr 2003; 11(3): 23-26.

119. Huang $\mathrm{H}$, Manton KG. The role of oxidative damage in mitochondria during aging: a review. Front Biosci 2004; 9: 1100-1117.

120. Logan AC, Wong C. Chronic fatigue syndrome: oxidative stress and dietary modifications. Altern Med Rev 2001; 6: 450-459.

121. Manuel y Keenoy B, Moorkens G, Vertommen J, De Leeuw I. Antioxidant status and lipoprotein peroxidation in chronic fatigue syndrome. Life Sci 2001; 68: 2037-2049.

122. Richards RS, Roberts TK, McGregor NR, Dunstan RH, Butt HL. Blood parameters indicative of oxidative stress are associated with symptom expression in chronic fatigue syndrome. Redox Rep 2000; 5: 35-41.

123. Fulle S, Mecocci P, Fano G, Vecchiet I, Racciotti D, Cherubini A, Pizzigallo E, Vecchiet L, Senin U, Beal MF. Specific oxidative alterations in vastus lateralis muscle of patients with the diagnosis of chronic fatigue syndrome. Free Radic Biol Med 2000; 29: 12521259.

124. Dianzani MU. Lipid peroxidation and cancer. Crit Rev Oncol Hematol 193; 15: 125-147.

125. Pall ML. Elevated, sustained peroxynitrite levels as the cause of chronic fatigue syndrome. Med Hypoth 2000; 54: 115-125.

126. Nicolson GL, Poste G, Ji T. Dynamic aspects of cell membrane organization. Cell Surface Rev 1977; 3: 1-73.

127. Subczynski WK, Wisniewska A. Physical properties of lipid bilayer membranes: relevance to membrane biological functions. Acta Biochim Pol 2000; 47: 613-625.

128. Radi R, Rodriguez M, Castro L, Telleri R. Inhibition of mitochondrial electronic transport by peroxynitrite. Arch Biochem Biophys 1994; 308: 89-95.

129. Kanno T, Sato EE, Muranaka S, Fujita H, Fujiwara T, Utsumi T, Inoue M, Utsumi K. Oxidative stress underlies the mechanism for $\mathrm{Ca}\left(2^{+}\right)$-induced permeability transition of mitochondria. Free Radic Res 2004; 38: 27-35.

130. Nicolson GL. Lipid replacement as an adjunct to therapy for chronic fatigue, anti-aging and restoration of mitochondrial function. J Am Nutraceutical Assoc 2003; 6(3): 22-28.

131. Nicolson GL, Ellithrope RR. Lipid replacement and antioxidant nutritional therapy for restoring mitochondrial function and reducing fatigue in chronic fatigue syndrome and other fatiguing illnesses. J Chronic Fatigue Syndr 2006; 13(1): 57-68. 
132. Ellithorpe RR, Settineri R, Nicolson GL. Reduction of fatigue by use of a dietary supplement containing glycophospholipids. J Am Nutraceutical Assoc 2003; 6(1): 23-28.

133. Mansbach CM, Dowell R. Effect of increasing lipid loads on the ability of the endoplasmic reticulum to transport lipid to the Golgi. J Lipid Res 2000; 41: 605-612.

134. Seidman M, Khan MJ, Tang WX, Quirk WS. Influence of lecithin on mitochondrial DNA and age-related hearing loss. Otolaryngol Head Neck Surg 2002; 127: 138-144.

135. Piper BF, Linsey AM, Dodd MJ. Fatigue mechanism in cancer. Oncol Nurs Forum 1987; 14: 17-23.

136. Nicolson GL, Ellithorpe RR, Ayson-Mitchell C, Jacques B, Settineri R. Lipid Replacement Therapy with a glycophospholipid-antioxidant-vitamin formulation significantly reduces fatigue within one week, J Am Nutraceutical Assoc 2010; 13(1): 1115.

137. Colodny L, Lynch, K, Farber, C, Papish R, Phillips K, Sanchez M, Cooper K, Pickus O, Palmer D, Percy TB, Faroqui M, Block JB. Results of a study to evaluate the use of Propax to reduce adverse effects of chemotherapy. J Am Nutraceutical Assoc 2001; 3(1): 17-25.

138. Nicolson GL, Ellithorpe R, Settineri R. Dietary supplement Healthy Curb for reducing weight, girth, body mass, appetite and fatigue while improving blood lipid values with NTFactor Lipid Replacement Therapy. J Invest Myalgic Encephalomyelitis 2009; 3(1): $39-48$.

139. Calabrese V, Lodi R, Tonon C, D' Agata V, Sapienza M, Scapagnini G, Mangiameli A, Pennisi G, Stella AM, Butterfield DA. Oxidative stress, mitochondrial dysfunction and cellular stress response in Friedreichs ataxia. J Neurol Sci 2005; 233: 145-162.

140. Roberts RA, Laskin DL, Smith CV, Robertson FM, Allen EM, Doorn JA, Slikker W. Nitrative and oxidative stress in toxicology and disease. Toxiol Sci 2009; 112: 4-16.

141. Rosignol DA, Frye RE. Mitochondrial dysfunction in autism spectrum disorders: a systematic review and meta-analysis. Mol Psychiat 2011; e1-e25 (ahead of print).

142. Mazzio EA, Close F, Sollman KF. The biochemical and cellular basis for nutraceutical strategies to attenuate neurodegeneration in Parkinson's disease. Int J Mol Sci 2011; 12: 506-569.

143. Crook TH, Tinklenberg J, Yesavage J, Petrie W, Nunzi MG, Massari DC. Effects of phosphatidylserine in aged-associated memory impairment. Neurology 1991; 41: 644649.

144. Rahman I. Oxidative stress and gene transcription in asthma and chronic obstructive pulmonary disease: antioxidant therapeutic targets. Curr Drug Targets Inflamm Allergy 2002; 1: 291-315.

145. Yao H, Rahman I. Current concepts on oxidative/carbonyl stress, inflammation and epigenetics in pathogenesis of chronic obstructive pulmonary disease. Toxicol Appl Pharmacol 2011 Feb 4 (ahead of print). 
146. Kempuraj D, Madhappan B, Christodoulou S, Boucher W, Cao J, Papadopoulou N, Cetrulo CL, Theoharides TC. Flavonols inhibit proinflammatory mediator release, intracellular calcium ion levels and protein kinase $\mathrm{C}$ theta phosphorylation in human mast cells. Br J Pharmacol 2005; 145: 934-944.

147. Dai DF, Rabinovitch PS. Cardiac aging in mice and humans: the role of mitochondrial oxidative stress. Trends Cardiovasc Med 2009; 19: 213-220.

148. Dai DF, Johnson SC, Villarin JJ, Chin MT, Nieves-Cintron M, Marcinek DJ, Dom GW, Kang YJ, Prolla TA, Santana LF, Rabinovitch PS. Mitochondrial oxidative stress mediates angiotensin II-induced cardiac hypertrophy and Gaq overexpression-induced heart failure. Circ Res 2011; 108: 836-846

149. Rautiainen S, Akesson A, Levitin EB, Morgenstern R, Mittleman MA, Wolk A. Multivitimn use and the risk of myocardial infarction: a population-based cohort of Swedish women. Am J Clin Nutr 2010; 92: 1251-1256.

150. Peterson J, Dwyer J, Aldercreutz H, Scalbert A, Jacques P, McCullough ML. Dietary lignans: physiology and potential for cardiovascular disease risk reduction Nutr Rev 2010; 68: 571-603.

151. Houston MC, Egan BM. The Metabolic Syndrome. Pathophysiology, diagnosis, clinical aspects, prevention and nonpharmacologic treatment: emphasis on lifestyle modifications, nutrition, nutritional supplements, vitamins, minerals, antioxidants, weight management and exercise. J Am Nutraceutical Assoc 2005; 8(2): 3-83.

152. Nicolson GL. Metabolic syndrome and mitochondrial function: molecular replacement and antioxidant supplements to prevent membrane oxidation and restore mitochondrial function. J Cell Biochem 2007; 100: 1352-1369. 